\title{
The ambiguity of intelligent algorithms: job killer or supporting assistant
}

\author{
Anette Braun $^{1}$ • Axel Zweck ${ }^{1}$ Dirk Holtmannspötter ${ }^{1}$
}

Received: 28 July 2016 / Accepted: 16 October 2016/Published online: 30 October 2016

(C) The Author(s) 2016. This article is published with open access at Springerlink.com

\begin{abstract}
The history of industrialisation shows how new technologies triggered social and economic revolutions, and how traditional jobs were replaced or changed by the use of machines. There are signs of highly dynamic changes in the learning and working environment of the 21 st century, with serious global social consequences similar to the industrial revolution. In the working environment, computers assist people and reduce their workload in a variety of ways. With increasing computing power and advanced memory technologies, they master the basics of autonomous machine learning. Intelligent algorithms are increasingly taking control, with the result that in many occupations, decisions are already routinely taken by software systems and not by people any more. Within just a few decades, information technology and its associated technological requirements have become the catalyst for a highly industrialised society. Developments in microelectronics are progressing at exponential speed, which will also have far-reaching social consequences for vocational fields outside of the information and communication technologies. Impacts of the knowledge and information society include changes in the nature of work towards an increasingly important service sector and a significant increase in knowledge work. This is accompanied by a decline in the working
\end{abstract}

Anette Braun

braun_a@vdi.de; http://www.vditz-ibb.de

Axel Zweck

zweck@vdi.de; http://www.vditz-ibb.de

Dirk Holtmannspötter

holtmannspoetter@vdi.de; http://www.vditz-ibb.de

1 Innovationsbegleitung und Innovationsberatung, VDI

Technologiezentrum GmbH, VDI-Platz 1,

40468 Düsseldorf, Germany population (demographic change) and the need for a modified workplace design in context of the changed age structure of the workforce. This Paper intends to explore on basis of the findings from the most recent German Foresight Exercise (BMBF Foresight Cycle II), how technological innovations in the field of ICT will dramatically change structures and ways of communication, collaboration and work. Some alternative development paths and implications for the areas job, career, production and work are scrutinized and discussed. Possible developments depend on the degree of autonomy of computer systems and the extent to which humans lose control over these systems; while - of course - the boundaries between conceivable scenarios are fluid.

Keywords Job · Work · Career · Autonomous computer systems
Abbreviations
IT Information Technologies
ICT Information and Communication Technologies
BMBF Bundesministerium für Bildung und Forschung (German Research Ministry)

\section{Introduction}

The history of industrialisation shows how new technologies triggered social and economic revolutions, and how traditional jobs were replaced or changed by the use of machines. There are signs of IT-driven highly dynamic changes in the learning and working environment of the 21 st century, with serious global social consequences similar to the industrial revolution, such as the substitution of traditional jobs. Within just a few decades, information technology and its associated 
technological requirements have become the catalyst for a highly industrialised society. In contrast to historical developments there are new and different issues, induced by the developments in microelectronics that are progressing at exponential speed, which will also have far-reaching social consequences for vocational fields outside of the information and communication technologies. These developments hold immense innovation potentials for reducing costs and enhancing efficiency of routine-based professional tasks (even in knowledge-based occupations and professions such as medical services), and possibly even in research and development as well.

Impacts of the knowledge and information society include changes in the nature of work towards an increasingly important service sector and a significant increase in knowledge work. This is accompanied in many western countries by a decline in the working population (demographic change) and the need for a modified workplace design in context of the changed age structure of the workforce.

In the working environment, computers may further assist people and reduce their workload in a variety of ways. With increasing computing power and advanced memory technologies, they master the basics of autonomous machine learning [1]. Intelligent algorithms ${ }^{1}$ are increasingly taking control, with the result that in many occupations, decisions are already routinely taken by software systems and not by people any more. Hence, the question arises whether intelligent algorithms are job killers or whether they are rather supporting assistants.

On basis of the findings derived from the most recent national German Foresight process (Cycle II) ${ }^{2}$ this paper scrutinizes the potential implications of the "work colleague computer" and their possible ubiquity in everyday life in a narrative way for the areas work, production, job and career. (The boundaries between conceivable scenarios are fluid.) It argues that the spread of "autonomous computer systems" is driven by cost-efficiency but also by the necessity of providing an IT-based assistance for increasingly complex decisionmaking processes - increasingly in the middle class ${ }^{3}$ environment.

Furthermore, it suggests that the increasing number of complexly linked facts and parameters will dramatically

\footnotetext{
${ }^{1}$ The algorithm is the basic technique (computer programme) used to get the job done, while the intelligent algorithm is designed to allow the computer to learn on its own. http://computer.howstuffworks.com/question717.htm, https://www.wired.com/insights/2014/09/artificial-intelligence-algorithms-2/

${ }^{2}$ https://www.bmbf.de/de/mit-foresight-in-die-zukunft-schauen-930.html, Accessed 16 September 2016

3 There are many ideas and concepts of the "middle class", but no final, widely recognized definition in a sociological sense. In this paper, "middle class" is understood as "social class usually comprising of white-collar (non-manual) workers, lower-level managers, and small business owners, often constituting about one-third of the employed population of a country. The income of this class is higher than that of the working-class but lower than that of the uppermiddle class (doctors, engineers, lawyers, middle-size business owners) and upper class." http://www.businessdictionary.com/
}

change structures and ways of communication, collaboration and work. Possible development paths and dimensions depend on the extent to which humans lose or keep control over these computer systems. Like that, it aims at an adequate discussion of the socio-economic consequences and needs deriving from the spread of computer intelligence in everyday life.

\section{Background}

In the light of the ever-growing role of technology foresight and forecasting in strategic thinking [2], the most recent German national Foresight process ${ }^{4}$ identifies future global social challenges relating to Germany that will be relevant between now and 2030 with an emphasis on the social consequences [3-5]. On basis of the findings of this German Foresight Process (Cycle II), the basic assumption of this paper is that the increasing use of autonomous computer systems has extensive impacts on the working environment, on education and training, as well as on economic and social systems. Notably in that it is rather an "activity" that can be replaced by computers, and not an entire "profession", substitution of human capital is not limited to low-skilled fields of activity.

\section{Excursion: the German foresight cycle II}

BMBF Foresight Cycle II (2012-2014) ${ }^{5}$ is complementary to Cycle I and focuses on changed needs resulting e.g. from social transformation. The overriding aim of BMBF Foresight Cycle II is to identify social challenges at the interfaces between society and technology in the form of innovation seeds. As emphasised in the High-Tech Strategy 2020, the main innovation drivers are considered to be "new technologies, services, and new social developments or changes, but also global challenges to which solutions and responses need to be found" [6].

In light of this, the current Cycle II Foresight (20122014) identifies future global social challenges relating to Germany that will be relevant between now and 2030 with an emphasis on future social trends and challenges. With the completion of the search phase of the second cycle of the BMBF Foresight process, exciting results concerning future social and technological developments with a time horizon of 2030 are now available. The process addresses possible upheavals in the fields of health, research and innovation, education, business, politics and work. To this end, suitable knowledge banks are accessed,

\footnotetext{
${ }^{4}$ Cycle I Foresight (2007-2009) centred on a technology-oriented approach. BMBF Foresight Cycle II (2012-2014) 4 is complementary to Cycle I and focuses on changed needs resulting e.g. from social transformation.

${ }^{5}$ This Foresight process was conducted on a subcontractor basis by VDI Technologiezentrum $\mathrm{GmbH}$ in conjunction with the Fraunhofer Institute for Systems and Innovation Research (ISI)
} 
combined and prepared in appropriate ways. Apart from the original task of Foresight - to identify new trends and topics - the current challenges of Foresight processes lie in filtering a glut of multimedia information on a projectrelated basis, i.e. in deciding which of the many developments that are publicised around the world are particularly relevant to the ministry. Therefore, in addition to the departments' Foresight activities, BMBF Foresight Cycle II has concentrated on determining possible fields of action for overarching global social challenges.

The methodological approach is based on the assumption that innovations are resulting from a combination of technological developments ("technology push") and social requirements ("demand pull"). Therefore the method was consisting of three work stages and resulted in three separate result reports (see Fig. 1).

The first stage (A) comprises a balanced inventory of social changes that have a bearing on the future and which are significant to persons and organisations promoting research and innovation. It identified social trends (60 trend profiles) and derived social challenges (seven topic areas) [3].

The second stage (B) provides a comprehensive account of 11 research and technology perspectives with a generally consistent level of complexity and granularity. It is therefore well suited to providing non-technical people with an overview, while offering specialists in particular disciplines detailed insights into neighbouring fields [4].

The stories from the third stage (C) link social challenges to research and technology perspectives. This highlights possible socio-technical lines of development. Any discrepancies between the possible developments as portrayed in the stories, and desirable developments from the reader's point of view, are indicative of organisational tasks which will ultimately need to be addressed via a society-wide debate. The stories are intended to provoke such discussions [5]. Hence, apart from the original task of Foresight - to identify new trends and topics - the current German Foresight process links social challenges to research and technology perspectives, portrayed in short stories and trend profiles that are intended to offer food for thought and discourse, ranging from issues such as "do it yourself Germany" to "welfare competence" and "work colleague computer" [5]. On the latter the results of the German Foresight process demonstrate that a broad discussion of the issue is necessary to fully and adequately address future societal needs.

In the education sector these developments may have disruptive effects on lecturers and their attendance-based classes: they might be replaced by online lectures and, for classical universities, the question will arise of whether long-standing curricula are even still appropriate. Online universities may offer a more appropriate flexible, modular system instead of fixed curricula. It is possible that businesses will express their requirements in the form of specific teaching modules, and guarantee jobs for a certain number of graduates. As a result, assessment criteria and the reputation possibilities for universities may change fundamentally.

Great challenges will arise here for career guidance, for higher education course offerings, for the design of educational content and for the identification of future job market requirements.

The concept of general education will change, creating the challenge of regularly reviewing learning content for schools, vocational training, and university study.

However, because of the semantic arrangement of information, not only people but also computers are increasingly able to use and intelligently evaluate the internet as a knowledge pool in an automated manner. Ever greater volumes of data are available in machine-readable form - not least mass data (big data) from social networks that helps computers to learn how people think and take decisions.

As humans increasingly deal with robots on an everyday basis, contact between humans may decrease. This could create problems for citizens' social integration - or it may finally provide the necessary freedom and opportunity for person-toperson contact.

From an economic perspective, large companies in particular might stand to benefit from efficiency increases brought about by automation ${ }^{6}$ : While company profits might increase, they would be generated by ever fewer employees and some jobs might become obsolete. Ever fewer people may be required in the value creation process [7].

In the past, many jobs were created in the service sector, but these could themselves be heavily affected in the future [8]. The potential for substitution varies heavily among the different occupational skill levels, but lowskilled activities might be more affected by displacement effect. Critics fear that the digital revolution will fail to create enough new jobs, and that the concentration of wealth in the hands of the few will increase [7].

If computers or robots will be able to perform jobs in the future, which are currently done by humans, as in the manufacture of mobile phones in Asian low-wage countries, this will have a massive impact on global economic structures ${ }^{7}$. With intelligent manufacturing processes, the factories could return to the sales markets, creating enormous opportunities for Europe.

\footnotetext{
${ }^{6}$ Automation as defined in DIN standard V 19233: equipping a facility so that it operates wholly or partially without human involvement.

${ }^{7}$ As discussed for instance here: Rethink Robotics. http://www. rethinkrobotics.com/. Accessed 14 June 2016
} 
Fig. 1 The three work stages of Foresight Cycle II

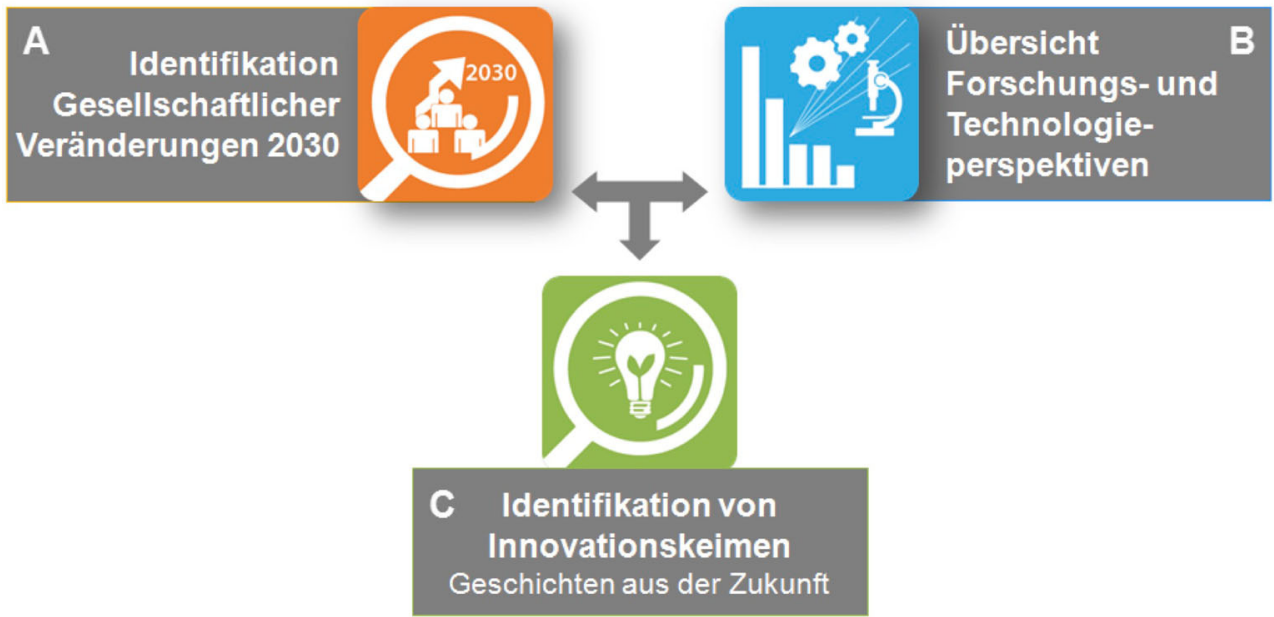

\section{Autonomous computer systems: a challenge for the middle class?}

This chapter argues that technological innovations in the field of ICT are driven by cost-efficiency but also by the necessity of providing an IT-based assistance for increasingly complex decision-making processes. It explores possible development paths depending on the extent to which humans lose or keep control over computer systems.

Increasingly, computers and autonomous robots will be able to assist - or take over - an increasing number of human activities. They will not only carry out complicated production steps completely by themselves, but will also perform thinking activities while delivering advisory and other services for knowledge workers and service providers. This creates new economic opportunities for Germany and its competitiveness against low-wage countries. In addition, developments in automation could be one approach to solving the skills shortage and reducing the burden of work on citizens. It may also change many existing job profiles and contribute to the emergence of new ones. Demand for suitably qualified personnel may produce opportunities for the job market.

However, it will also contribute to making a number of existing jobs superfluous. The elimination of low-skilled assembly-line jobs as a result of rationalisation could be followed by the elimination of supposedly skilled knowledge-worker jobs in the future [7,9]. A number of professional fields in which comparatively high incomes are earned - such as medicine and law - involve many routine tasks, which increasingly may be performed by information technologies. It is expected that many jobs will be eliminated or change significantly with farreaching challenges particularly for the middle class and for highly qualified professions: electronic medical expert systems in hospitals are already making diagnoses in hospitals, while on the world's high-frequency exchanges, autonomous computer algorithms trade in millisecond cycles. Modern text-synthesis algorithms could very soon write news articles on sports events or compile financial news into reports that are barely distinguishable from texts by human authors. The middle class could be increasingly affected by these change processes due to loss of income or unemployment $[10,11]$.

The question arises as to the distribution of the "automation dividend" and the design of future social systems. It would be helpful here to have a scientific discourse about guiding principles that describe a balanced relationship between human and digital labour. It is important to systematically identify the extent to which striving for (profit) optimisation is ethically justifiable when using automation to raise productivity: How should society deal with the elimination of further jobs through rationalisation? What can be done to ensure that the current young generation is adequately prepared for digital competency pressure and changing job profiles?

Hence it is necessary to ask on the one hand what consequences such a development will have for the working world and society in the future, and on the other hand, how Germany will position itself in the international field of "algorithm providers" [12].

\section{Possible development paths}

Driven by cost-efficiency and but also by the necessity of providing an IT-based assistance for increasingly complex decision-making processes, the possible development paths depend on the degree of autonomy of computer systems and the extent to which humans lose or keep control over these systems. The boundaries between conceivable scenarios are fluid, as outlined below in two extreme scenarios: extensive control and complete loss of control. 


\section{Humans keep control over computer systems}

A development where humans have extensive control over computer systems and their applications would assume maximum transparency in the development of software systems and applications. System architectures should have a modular structure wherever possible, and intermediate products shall be clearly defined. Users will have operational control over systems that have an exclusively supporting function. For example, important decisions are prepared by computer systems, but the actual decision is always taken by a person following an evaluation and control step. With this development path, there is less of an impact on many knowledge-based jobs since people retain decision-making powers and responsibilities. Computers here have supporting functions for decision-making, and their interfaces in all areas of life and work are geared towards humans.

If computers assist people to a greater extent in knowledgebased work processes in the future, this will result in numerous opportunities. This assistance could have a positive effect on the growing desire for time sovereignty. However, if computers become more independent, this could mean that work processes and the people involved in them have to orientate themselves to technical systems. Yet surely an orientation to human requirements is desirable here [13]. People who know how to use computers and intelligent algorithms optimally for their work will have the biggest opportunities in the job market. Furthermore, automation opens up a variety of new opportunities to promote inclusion in the working environment. Individual work steps that cause problems can be performed by automated systems, and as a result, humans can retain their position in the value chain.

\section{Computer systems become independent - humans lose control}

A development where humans completely lose control over computer systems and their applications would assume a massive spread of autonomous computer systems and big data replacing human intuition. Driven by cost-efficiency and the increasing inability of humans to take into account a large number of complexly linked facts and parameters in decision-making, computers would be used in ever more areas to make independent decisions that have direct or indirect consequences for humans. These systems would develop themselves independently, where humans are completely uninvolved (with IT specialists mainly ensuring that the systems do not fail.) An example for such a development is the increasing algo trading, where intelligent algorithms produce stock market reports, which in turn are analysed by other algorithms [14]. However, if assistance in the workplace goes so far that humans can increasingly be replaced by computer systems, job losses and sharp falls in income would be the consequence. It was estimated that up to $50 \%$ of all jobs in the sales, office, transport and logistics sectors as well as administration and services could be eliminated [8].

The growing independence of software systems is accompanied by a continuous increase in technological complexity. Technical backgrounds and processes are ever less comprehensible to normal users because of their fast pace of development. Because of the large number of technical systems that surround humans, the vast majority of users are no longer expected to understand the underlying technology. Here humans are the direct driver of a loss of control which they tolerate. Even IT specialists usually only understand some portions of networked systems. The result of the interplay of complex feedback systems is becoming ever less comprehensible to individual people. Consequently, it is difficult to check whether decisions or solutions that are taken or calculated by computer systems are actually optimal.

If human correction is eliminated, it is possible that autonomous decisions by computer systems will be "neutral" and "impartial", but on the other hand they could result in uncompromising harshness towards the people affected by them. When it comes to dealing with temporary payment difficulties on a home loan, for instance, algorithmic decisions may have a different outcome than the decision taken by a bank clerk, who is familiar with the borrower. Moreover, undetected system errors may have serious consequences such as incorrect calculations and wrong decisions. This creates the challenge of preserving transparency and control capabilities for humans in the case of autonomous decisions by computer systems and their innovations. Here, as in other areas too, questions of standardisation need to be answered.

The discussion about the dependence of humans on technical systems is not new. However, from today's perspective, it is difficult to imagine the dimensions that a potential failure of networked technological systems might have in the future. It will be a key requirement in the future development of technology and innovations to consider the risks of technical failures or malfunctions. Related to this, the issue of liability should be addressed in case autonomous systems cause damage.

\section{Work colleague computer}

The German Foresight Process has portrayed in short stories ${ }^{8}$ how a "work colleague computer" that does so many jobs, works around the clock, never gets tired, and doesn't make any careless mistakes, might influence the everyday life in 2030 and beyond. On the basis of these results and in fictional form, this chapter tries to illustrate challenges for the areas work, production, job and career. Potential implications of

\footnotetext{
${ }^{8}$ The stories were developed in the frame of the BMBF Foresight Cycle II and published in Volume 3 of results from the search phase of BMBF Foresight Cycle II.
} 
the "work colleague computer" and their possible ubiquity in everyday life are scrutinized in a narrative way, where the boundaries between conceivable scenarios are fluid. In this way, they may serve as a point of departure for further public discussions and dialogue.

\section{Work colleague computer: working environment}

A journalist sits in her home office, a cup of coffee in her hand. The computer has analysed yesterday evening's football World Cup Final overnight, and written up a punchy draft article. News reports have been created automatically for some time now, and often they are even published on the online news site without any human intervention. It's a great thing, as it means that the journalist has more time for editorial work that is more challenging and more interesting. The computer is also helpful for doing technical research. To start with, it automatically compiles relevant facts on almost any topic. Not only that, it prepares and organises its findings in a presentation. While the journalist was sleeping, the computer did the research for an upcoming interview with a professor of informatics about autonomous computer systems. It's interesting to think about where it all might lead to. The journalist quickly skims through the prepared summary of the current state of development. The presentation ranges from automated business analysis to the evaluation of gigantic data volumes to detect all kinds of dangers, to the percentage of doctors who currently use intelligent diagnostic systems on an everyday basis, which frees up time to spend talking to their patients. This figure recently reached $85 \%$. The journalist is always surprised at how the significance of technology is changing in many occupations. His personal digital assistant, for example, has become indispensable as it performs all the secretarial duties: the computer routinely arranges appointments, places orders, answers calls and helps with management tasks. The computer informs the journalist that the virtual interview with the informatics professor will start in $5 \mathrm{~min}$. Thanks to a holographic projection system, the journalist sits directly opposite the interviewee and saves a lot of time and money to be spent on alternative travel. However, since the journalist now only rarely needs to leave the house for interviews, personal contact to human beings has become seldom.

\section{Work colleague computer: production environment}

A labourer in production for an aircraft manufacturer has a mobile robot assistant by his side to help him with all the assembly work. The robot lifts heavy parts and sometimes even fits a tiny screw if it's too fiddly for the labourer, who quickly learned to work with the robot assistant intuitively, but nevertheless took a training course to learn what the robot assistant is capable of. After a phase of getting to know each other that lasted several weeks, the robot learned to understand every spoken word, and even to recognise gestures and facial expressions. A few weeks ago, the robot rushed to the labourer's aid when it saw that his face was contorted by pain. He had trapped his foot, but the robot quickly managed to free him. The aircraft manufacturer now uses more than 100 robot assistants in production just at this site, and has significantly expanded its global market position. The robot assistants have made a large contribution to this success, even though some production jobs have been lost. Cost-intensive work to rectify assembly defects is now rarely necessary. But robot assistants occasionally break down or report a malfunction. In an internal pilot project, a team of robots is working autonomously on individual assembly steps. Their perceptions, activities and communication with each other are fully monitored by collecting together all the data and information they generate in a cloud, so that it can be analysed someplace in the world. Initial concerns about data security were allayed. The aircraft manufacturer is one of the global pioneers in using robot assistants in production. The company's management quickly recognised the potentials, and took the investment risk after a pilot phase. For some time now, the company has partnered with a mobile phone provider. They want to make smartphones in Germany and are interested in the aircraft manufacturer's positive experiences with the robot assistants' fine motor skills. Thanks to the use of robots, they will soon be ready to relocate production from Asia to Germany, and start making mobile devices for the consumer goods market in Germany again.

\section{Work colleague computer: services}

A family is looking forward to their summer holiday in Spain: their suitcases are packed and the driverless taxi is about to come and collect them. Their luggage is checked in automatically at the airport. The family won't see their bags again until they get to their hotel room. Before the family leaves their house, they set the home automation controller to holiday mode. The controller switches lights on and off to make it look like someone's at home, and even briefly opens windows safely located on the first floor to the tilt position. From the outside, you would hardly know that the house is unoccupied. Actually it's not really vacant, as the home robot will water the flowers and tell them straight away if anything untoward happens in the house or garden.

The family enjoys the almost silent journey in the separate taxi lane. Journey times have fallen dramatically because of the taxi lane, and accidents have become a rarity. The city centre has been turned into a pilot area for testing autonomous transport systems, and is even closed off to private cars. Most passenger and goods transportation takes place via 
autonomous and driverless taxis, buses, trains and parcel drones. The journey ends almost directly in front of the check-in machine. This is possible because the luggage was transported separately in advance, which means it takes much less time to get out of the car. As they have some time to spare, the family goes into a fast-food restaurant, places their order at a display terminal, pays and receives an order slip. They can use this to $\log$ in at any table they like and the food is automatically delivered to the table. A service robot with a keepwarm function serves them. Although this is less personal than before, it does mean that the food is still piping hot when it arrives at the table. Many restaurant chains now use service robots like this, which enables them to stay open $24 \mathrm{~h}$ a day. However, during the flight, a flight attendant is available for the board service, not a robot.

\section{Work colleague computer: new job models}

While lifelong learning is omnipresent, it has become easier to study at a renowned international university, as nearly all universities worldwide offer affordable distance learning courses. In the market for creative production an open, global creative competition takes place. The best ideas count, and even for large companies it's "in" to award assignments to less wellknown creative thinkers (designers, etc.).

Following a downturn in sales in recent years, this has now led the established agencies to adopt new business models. These changes have been caused not least by new automation technologies, which make it possible for aspiring one-person design agencies to present clients with professional product designs. For example, a single freelance designer produces demonstrations of his designs overnight on a $3 \mathrm{D}$ printer. In the past, it used to take model-makers days to build product designs by hand.

\section{Conclusions}

An answer to the initial question of the paper ("Are intelligent algorithms job killers or supporting assistants?") clearly is that the spread of autonomous systems requires an adequate discussion of the challenges and the socio-economic consequences, which in turn depend on the extent to which humans lose or keep control over these computer systems.

In future, computers will be so powerful that they will probably be able to take over tasks from knowledge workers. One key driver of this development is that a large part of human knowledge will be stored digitally in the future and be accessible to computers via cloud computing. With the help of big data, cognitive computer systems can detect hidden patterns and have become capable of learning, like humans. As a result, work processes can be made more efficient and therefore more profitable. Doctors, nursing staff and so on would therefore once again have more time to spend with patients, and people generally might have more (free) time for conversation, neighbourhood services, family and friends. This opens up opportunities for Germany to increase its competitiveness, and at the same time there is the prospect that future automation technologies will produce interesting new sales markets. Furthermore, a possible skills shortage could be alleviated by using computers and robots in many fields.

In factories, robots are able to take over physically strenuous and also difficult work in close proximity to humans. These machines are able to recognise humans and their movements, thus minimising the risk of injury. In the future, robots will also be able to correctly interpret the gestures and facial expressions of humans in their surroundings. As a result, they can be used as flexible and mobile robot assistants, e.g. in assembly. In future, robots could be capable of performing delicate and complex production steps that previously could only be done by hand (e.g. assembling a mobile phone). New, fully automated German production facilities would therefore have the potential in the future to compete against factories in low-wage countries. Furthermore, automation opens up a variety of new opportunities to promote inclusion in the working environment. Individual work steps that cause problems can be performed by automated systems, and as a result, humans can retain their position in the value chain.

It is entirely possible that in the near future, automation will also impact heavily on the service sector. Many service offerings could be improved by automation in terms of the availability and scope of services. By 2030, robots, drones and automatons might be able, $24 \mathrm{~h}$ a day, to serve food, deliver parcels, transport people, offer supermarket shopping, answer calls in call centres without queueing, etc. Significant ecological effects can be expected in passenger and goods transportation as a result of efficiency enhancements and green propulsion technologies.

However, more widespread use of computers in the occupational fields of knowledge workers and service providers may lead to competition for jobs between intelligent machines and humans. A new understanding of the future division of labour and role allocation between humans and machines is needed here. The question also arises of the distribution of wealth, if wealth is increasingly generated by machines. Job profiles could continually change with the steady growth of computer power, or lose much of their importance to humans. It is anticipated that many tasks and jobs in management, organisation, reporting and administration could be eliminated. This would result in constantly changing requirements for further training and qualifications. At the moment it is still unclear as to which new occupations will be created in connection with managing, monitoring and maintaining robots and networks, data analysis, and software and algorithm development, and how long demand for such new occupations will last. 
Especially with the increasing possibilities for digital communication and working, the freedom to do many work activities from home must not lead to an excessive reduction in personal contact. The widespread use of digital assistants and robots makes technical dependencies conceivable, while new questions arise concerning data privacy and data security. As innovations of this kind emerge, protective measures against malfunctions, functional failures and manipulation would need to be developed.

Not only will cognitive computer systems become ever more powerful, in the future they may also be able to optimise themselves, i.e. to change by themselves. These changes should only take place within a defined framework, not in an uncontrolled manner. As they become increasingly powerful and independent, cognitive computer systems have the potential to become competitors for jobs. This is true not only for pure assembly work, but also e.g. for engineering design services.

The primary challenges resulting from automation in the service sector are those of job design and preserving jobs. Many job profiles could substantially change as a result of collaboration with computers and robots. Humans should not have to orientate themselves to machines. Instead, machines should orientate themselves to humans. One of the greatest challenges here will surely be to create new fields of activity for employees in areas where tasks are increasingly being performed by computers and robots.

Open Access This article is distributed under the terms of the Creative Commons Attribution 4.0 International License (http:// creativecommons.org/licenses/by/4.0/), which permits unrestricted use, distribution, and reproduction in any medium, provided you give appropriate credit to the original author(s) and the source, provide a link to the Creative Commons license, and indicate if changes were made.

\section{References}

1. Nötges T (2013) Von künstlicher Intelligenz und Büromaterial. http://www.basicthinking.de/blog/2013/11/19/von-kuenstlicher- intelligenz-und-bueromaterial-googles-rechner-erkennenpapierschredder-angeblich-besser-als-jeder-mensch/. Accessed 16 June 2016

2. Braun A, Holtmannspötter D, Korte S, Rijkers-Defrasne S, Zweck A (2013) „Technologieprognosen - Internationaler Vergleich 2013“. VDI Technologiezentrum GmbH (ed) ZTC 97

3. Zweck et al. (2015) Forschungs- und Technologieperspektiven 2030, Ergebnisband 1 zur Suchphase von BMBF Foresight Zyklus II, Zukünftige Technologien. http://www.vditz. de/fileadmin/media/VDI_Band_100_C1.pdf. Accessed 09 June 2016

4. Zweck et al. (2015) Forschungs- und Technologieperspektiven 2030, Ergebnisband 2 zur Suchphase von BMBF Foresight Zyklus II, Zukünftige Technologien. http://www.vditz. de/fileadmin/media/VDI_Band_101_C1.pdf. Accessed 09 June 2016

5. Zweck et al. (2015) Forschungs- und Technologieperspektiven 2030, Ergebnisband 3 zur Suchphase von BMBF Foresight Zyklus II, Zukünftige Technologien. http://www.vditz. de/fileadmin/media/VDI_Band_102_C1.pdf. Accessed 09 June 2016

6. BMBF (2010) Ideen. Innovation. Wachstum. Hightech-Strategie 2020 für Deutschland. Bonn, Berlin

7. Brynjolfsson E, McAfee A (2011) Race against the machine: how the digital revolution is accelerating innovation, driving productivity, and irreversibly transforming employment and the economy. Digital Frontier Press, Lexington

8. Frey CB, Osborne MA (2013) The Future of Employment: How susceptible are jobs to computerisation? http://www.oxfordmartin. ox.ac.uk/downloads/academic/The_Future_of_Employment.pdf. Accessed 14 June 2016

9. Rifkin J (1997) Das Ende der Arbeit und ihre Zukunft: Neue Konzepte für das 21. Jahrhundert. Campus, New York

10. Grötker R (2013) Computer machen die Arbeit. Was machen wir. http://www.heise.de/tr/artikel/Computer-machen-die-Arbeit-wasmachen-wir-2158035.html. Accessed 14 June 2016

11. Cowen T (2013) Average is over: powering America beyond the Age of the great stagnation. Dutton, New York

12. Ford M (2009) The lights in the tunnel: automation, Accelerating technology and the economy of the future. CreateSpace Independent Publishing Platform, p 1

13. Kurz C, Rieger F (2013) Arbeitsfrei: Eine Entdeckungsreise zu den Maschinen, die uns ersetzen. Riemann Verlag, Munich

14. Rieger F (2012) Roboter müssen unsere Rente sichern. http://www. faz.net/aktuell/feuilleton/debatten/automatisierungsdividende-fueralle-roboter-muessenunsere-rente-sichern-11754772.html. Accessed 14 June 2016 